\title{
PENGARUH KUALITAS PRODUK, PROMOSI DAN CITRA MEREK TERHADAP KEPUTUSAN PEMBELIAN KARTU XL BUSINESS SOLUTION PADA PT. ACTIVATE ASIA
}

\author{
Syarah Afriyani, Lucy Nancy
}

*) Dosen Tetap Program S1 Jurusan Manajemen Fakultas Ekonomi dan Bisnis Universitas Satya Negara Indonesia.

Email: syarah.afriyani@gmail.com; lucynancysim@gmail.com

\begin{abstract}
This study aims to determine the effect of product quality, promotion and brand image on the decision to purchase XL Business Solution cards at PT. Activate Asia. This research is a causal research, the population in this study are employees of PT. Activate Asia, which uses the XL Business Solution card, totaling 130 employees. The sampling technique is probability sampling and uses the Slovin formula to produce 98 samples. The data analysis method used in this study is multiple linear regression analysis by performing instrument tests, classical assumption tests and hypothesis testing with the help of SPSS 23 software. The results show that simultaneously the variables of product quality, promotion and brand image have a significant effect on purchasing decisions. And partially the variables of product quality, promotion and brand image have a significant effect on purchasing decisions
\end{abstract}

Keywords: Purchasing Decisions, Product Quality, Promotion, Brand Image.

PENDAHULUAN

Penggunaan internet saat ini menjadi salah satu kebutuhan pokok bagi masyarakat, dengan adanya internet siapapun dapat menggunakan dan mengakses konten yang sesuai dengan keinginan dan kebutuhannya. Akan tetapi, untuk dapat menggunakan internet kita membutuhkan sebuah koneksi agar dapat tersambung dengan jaringan internet maka dari itu kita membutuhkan kartu internet atau yang biasa kita sebut provider. Kartu internet saat ini menjadi salah satu pilihan yang sangat dipertimbangkan oleh masyaratakat untuk mendapatakan kelancaran dalam berkomunikasi digital melalui smartphone. Saat ini banyak produk kartu internet yang dapat kita ditemui dipasaran, seperti Telkomsel, XL Axiata, Indosat, 3, dan Smartfren. Persaingan bisnis ini menjadi sangat ketat dengan bertambahnya pengguna smartphone di era digital ini. Dengan ini, setiap perusahaan berlomba-lomba untuk membuat ide dan penawaran paling menarik hingga dapat meraih pangsa pasar dan pelanggan serta memenuhi kebutuhan penggunanya, salah satunya yang dilakukan oleh XL Axiata yang membuat ide untuk menciptakan kartu XL Business Solution, kartu prabayar yang secara khusus dibuat untuk perusahaan-perusahaan agar mempermudah pekerjaan setiap perusahaan atau startup yang sedang berkembang dan ingin usahanya terintegrasi. 
Menurut data pengguna kartu internet (Sumber: Bisnis.com) pada tahun 2019, peringkat pertama ditempatkan oleh Simpati dengan jumlah 170,9 juta pengguna, kedua ditempatkan oleh Indosat dengan jumlah pengguna 58,7 juta pengguna dan XL Axiata menempati peringkat ketiga dengan jumlah pengguna 55,5 juta. Sedangkan khusus untuk kartu XL Business Solution pada tahun 2019 mengalami fluktuasi yang sangat drastis dengan didorongnya promosi yang dikeluarkan oleh pihak XL Axiata. Berikut adalah gambaran khususnya:

Sumber: Bisnis.com (2019)

Sumber: Data Penjualan XL

Berdasarkan data tersebut, Fenomena yang terjadi pada keputusan pembelian kartu X1
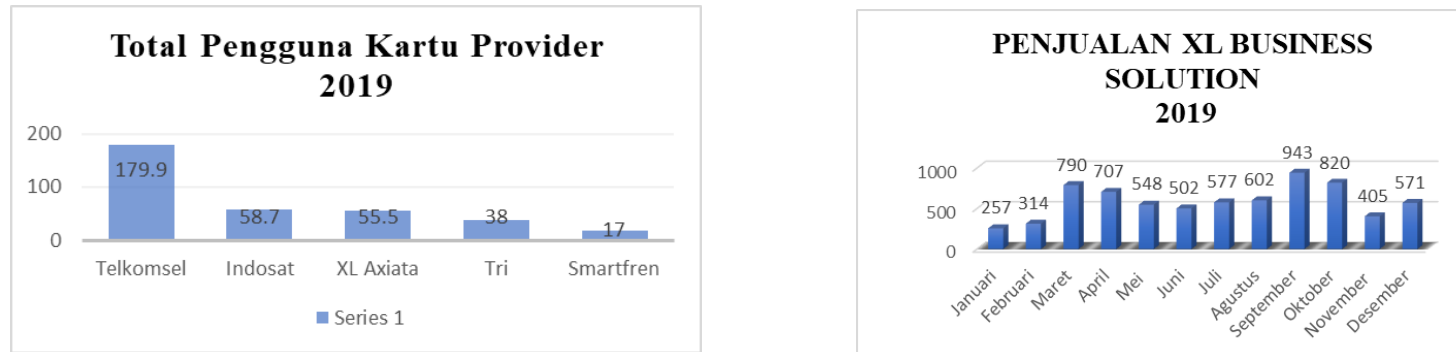

Business Solution adalah terjadinya fluktuasi pembelian kartu X1 Business Solution pada tahun 2019. Dapat dilihat dari data penjualan kartu Xl Business Solution pada Gambar 1.1, terjadi peningkatan penjualan yang sangat signifikan pada bulan Maret dan terjadi penurunan yang drastis setiap bulan nya.

Berdasarkan Latar Belakang diatas, peneliti tertarik memilih judul "PENGARUH KUALITAS PRODUK, PROMOSI DAN CITRA MEREK TERHADAP KEPUTUSAN PEMBELIAN KARTU XL BUSINESS SOLUTION PADA PT.ACTIVATE ASIA”

\section{TINJAUAN PUSTAKA}

\section{Pengertian Keputusan Pembelian}

Keputusan Pembelian ialah, "Consumer buyer behavior refers to the buying behavior of final consumers - individuals and households that buy goods and services for personal consumption", pengertian tersebut dapat diartikan bahwa perilaku keputusan pembelian mengacu pada perilaku pembelian akhir dari konsumen, baik individual, maupun rumah tangga yang membeli barang dan jasa untuk konsumsi pribadi.

\section{Pengertian Kualitas Produk}

Kualitas Produk adalah segala sesuatu yang dapat di tawarakan di pasar, untuk memuaskan kebutuhan dan keinginan consume. Produk terdiri atas barang, jasa, pengalaman, events, orang, tempat, kepemilikan, organisasi, informasi dan ide.

\section{Pengertian Promosi}

Promosi adalah alat komunikasi yang menginformasikan pelanggan potensial tentang keberadaan produk, dan membujuk mereka bahwa produk tersebut memiliki kemampuan yang memuaskan. 


\section{Pengertian Citra Merek}

Merek adalah nama, istilah, tanda, simbol, atau desain atau kombinansinya yang bertujuan untuk mengidentifikasikan barang dan jasa yang membedakan suatu produk dengan produk saingan.

\section{METODE PENELITIAN}

\section{Lokasi dan Waktu Penelitian}

Penelitian ini di lakukan di PT. Activate Asia yang berlokasi pada Jl. Ciputat Raya No.12, RW.10, Jakarta Selatan, Daerah Khusus Ibukota Jakarta 12240. Waktu Penelitian ini dilakukan pada bulan Maret - Juni 2020.

\section{Populasi dan Sampel}

Populasi dalam penelitian ini adalah 130 karyawan PT. Activate Asia yang menggunakan kartu XL Business Solution. Penilitian ini menggunakan teknik probability sampling dengan metode simple random sampling. Rumus yang digunakan pada penelitian ini adalah Slovin, maka mendapatkan jumlah sampel sebesar 98 sampel.

\section{Desain Penelitian}

Dalam penelitian ini desain yang digunakan adalah desain penelitian kausal, yaitu penelitian untuk mengetahui pengaruh antara satu atau lebih variabel bebas (independent variabel) terhadap variabel terikat (dependent variabel).

\section{Hipotesis Statistik}

H01 : Tidak terdapat pengaruh antara kualitas produk, promosi dan citra merek secara simultan terhadap keputusan pembelian

Ha1 : Terdapat pengaruh antara kualitas produk, promosi dan citra merek secara simultan terhadap keputusan pembelian

H02 : Tidak terdapat pengaruh antara kualitas produk terhadap keputusan pembelian

Ha2 : Terdapat pengaruh antara kualitas produk terhadap keputusan pembelian

H03 : Tidak terdapat pengaruh antara promosi terhadap keputusan pembelian

Ha3 : Terdapat pengaruh antara promosi terhadap keputusan pembelian

H04 : Tidak terdapat pengaruh antara citra merek terhadap keputusan pembelian

Ha4 : Terdapat pengaruh antara citra merek terhadap keputusan pembelian

\section{Definisi Operasional}

\section{Variabel Terikat/Dependen (Y)}

Keputusan Pembelian merupakan bagian dari perilaku konsumen perilaku konsumen yaitu studi tentang bagaimana individu, kelompok, dan organisasi 
memilih, membeli, menggunakan, dan bagaimana barang, jasa, ide atau pengalaman untuk memuaskan kebutuhan dan keinginan mereka.

\section{Variabel Bebas/Independen (X)}

a. Kualitas produk adalah karakteristik dari suatu produk atau jasa yang menunjang kemampuannya untuk memuaskan kebutuhan pelanggan. Kualitas produk merupakan kemampuan suatu produk dalam memenuhi keinginan konsumen

b. Promosi adalah upaya untuk memberitahukan atau menawarkan produk dan manfaat dari sebuah produk dengan tujuan menarik calon konsumen untuk membeli atau mengkonsumsinya.

c. Merek adalah nama, istilah, symbol, atau desain maupun kombinasi di antaranya yang dimaksudkan untuk mengidentifikasikan barang atau jasa seorang penjual atau sekelompok penjual dan membedakannya dari barang atau jasa para pesaing

\section{Metode Pengumpulan Data}

Metode pengumpulan data yang digunakan dalam penelitian ini adalah:

a. Penelitian Kepustakaan (Library Research), penelitian yang bertujuan untuk mengumpulkan data dan informasi melalui bantuan bermacam-macam material yang terdapat di ruangan perpustakaan serta bahan-bahan buku bacaan lain yang berhubungan dengan masalah yang diteliti

b. Kuesioner, merupakan metode pengumpulan data yang dilakukan dengan cara memberikan pernyataan tertulis yang akan dibagikan kepada responden, yaitu para karyawan PT. Activate Asia

\section{Jenis Data}

a. Data primer adalah data yang di peroleh dari sumber yang langsung mengalami suatu peristiwa dan bersifat mentah belum diolah. Data primer dalam penelitian ini adalah kuisioner yang masih perlu diolah lebih lanjut

b. Data sekunder adalah data yang diperoleh dari dokumen, laporan, yang sudah jadi atau diolah yang berhubungan dengan objek yang akan diteliti.

\section{HASIL DAN PEMBAHASAN}

\section{Uji Statistik Deskriptif}

\begin{tabular}{|l|c|c|c|c|c|c|}
\hline & N & Range & Minim um & Maxim um & Mean & $\begin{array}{c}\text { Std. } \\
\text { Deviation }\end{array}$ \\
\hline $\begin{array}{l}\text { KEPUTUSAN } \\
\text { PEMBEL IAN }\end{array}$ & 100 & 106 & 88 & 194 & 141.45 & 19.462 \\
\hline KUAL TAS PRODUK & 100 & 67 & 53 & 120 & 88 & 12.09 \\
\hline PROMOSI & 100 & 72 & 48 & 120 & 84.58 & 13.451 \\
\hline CITRAMEREK & 100 & 73 & 62 & 135 & 104.46 & 11.58 \\
\hline Valid N (listwise) & 100 & & & & & \\
\hline
\end{tabular}

sumber: Hasil Pengolahan Data, 2020 
Berdasarkan hasil pengujian statistik deskriptif pada tabel 4.5 dapat disimpulkan sebagai berikut:

- Keputusan Pembelian memiliki nilai minimum sebesar 88, nilai maximum sebesar 194, nilai mean sebesar 141,45 dan std deviation sebesar 19,462.

- Kualitas Produk memiliki nilai minimum sebesar 53, nilai maximum sebesar 120, nilai mean sebesar 88,00 dan std deviation sebesar 12,090.

- Promosi memiliki nilai minimum sebesar 48, nilai maximum sebesar 120 , nilai mean sebesar 84,58 dan std deviation sebesar 13,451.

- Citra Merek memiliki nilai minimum sebesar 62, nilai maximum sebesar 135, nilai mean sebesar 104,46 dan std deviation sebesar 11,580.

\section{Uji Normalitas Asumsi Dasar}

\begin{tabular}{|l|c|c|c|c|c|c|}
\hline \multicolumn{1}{|c|}{ Tests of Normality } \\
\cline { 2 - 8 } & \multicolumn{2}{|c|}{ Kolmogorov-Smirnov $^{\text {a }}$} & \multicolumn{3}{c|}{ Shapiro-Wilk } \\
\hline Statistic & $\mathrm{df}$ & Sig. & Statistic & $\mathrm{df}$ & Sig. \\
\hline PEPUTUSAN & 0.06 & 98 & $.200^{*}$ & 0.977 & 98 & 0.089 \\
KUALITAS PRODUK & 0.084 & 98 & 0.083 & 0.981 & 98 & 0.171 \\
PROMOSI & 0.082 & 98 & 0.099 & 0.978 & 98 & 0.103 \\
CITRA MEREK & 0.087 & 98 & 0.065 & 0.982 & 98 & 0.21 \\
\hline
\end{tabular}

*. This is a lower bound of the true significance.

a. Lilliefors Significance Correction

Sumber: Hasil Pengolahan Data, 2020

Berdasarkan tabel diatas dapat dilihat bahwa hasil uji normalitas menunjukan output sebagai berikut:

- Variabel Keputusan Pembelian menghasilkan sig. 0,200 > 0,05 maka dapat disimpulkan bahwa data pada variabel Y berdistribusi normal

- Variabel Kualitas Produk menghasilkan sig. 0,083 > 0.05 maka dapat disimpulkan bahwa data pada variabel $\mathrm{X} 1$ berdistribusi normal

- Variabel Promosi menghasilkan sig. 0,099 > 0.05 maka dapat disimpulkan bahwa data pada variabel X2 berdistribusi normal

- Variabel Citra Merek menghasilkan sig. 0,065 > 0.05 maka dapat disimpulkan bahwa data pada variabel X3 berdistribusi normal 


\section{Uji Asumsi Klasik}

\section{Uji Normalitas Data Residual}

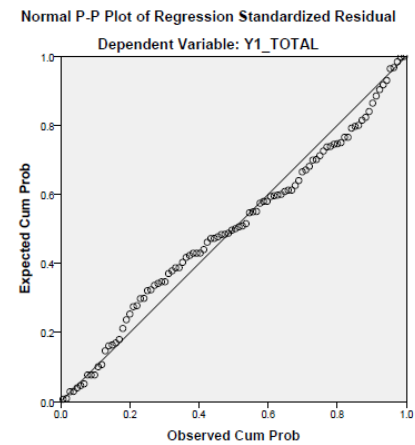

Sumber: Hasil Pengolahan Data, 2020

Berdasarkan hasil uji normalitas Histogram P-Plot pada gambar diatas, dapat disimpulkan bahwa data berdistribusi mengikuti arah diagonal, maka dapat dikatakan bahwa data berdistribusi dengan normal.

\section{Uji Multikolinearitas}

\begin{tabular}{|c|c|c|c|c|c|c|c|}
\hline \multicolumn{8}{|c|}{ Coefficients $^{a}$} \\
\hline \multirow{2}{*}{ Model } & \multicolumn{2}{|c|}{$\begin{array}{c}\text { Unstandardized } \\
\text { Coefficients }\end{array}$} & \multirow{2}{*}{\begin{tabular}{|c|c|}
$\begin{array}{c}\text { Standardiz } \\
\text { ed } \\
\text { Coefficient } \\
\text { s }\end{array}$ \\
Beta
\end{tabular}} & \multirow{2}{*}{$\mathrm{t}$} & \multirow{2}{*}{ Sig. } & \multicolumn{2}{|c|}{$\begin{array}{l}\text { Collinearity } \\
\text { Statistics }\end{array}$} \\
\hline & B & Std. Error & & & & Tolerance & VIF \\
\hline (Constant) & 24.581 & 13.171 & & 1.866 & 0.065 & & \\
\hline KUALITAS PRODUK & 0.492 & 0.187 & 0.308 & 2.632 & 0.01 & 0.385 & 2.597 \\
\hline PROMOSI & 0.3 & 0.15 & 0.22 & 2.001 & 0.048 & 0.436 & 2.294 \\
\hline CITRA MEREK & 0.466 & 0.17 & 0.275 & 2.741 & 0.007 & 0.524 & 1.909 \\
\hline
\end{tabular}

Sumber: Hasil Pengolahan Data, 2020

Berdasarkan tabel diatas dapat diketahui bahwa nilai tolerance untuk variabel kualitas produk (X1) 0,385 >0,1, variabel promosi (X2) adalah sebesar 0,436 $>0,1$ dan variabel citra merek (X3) adalah sebesar 0,524 > 0,1. Sedangkan nilai VIF (Variance Infaction Factor) untuk variabel kualitas produk (X1) adalah sebesar 2,597 $<10,00$, variabel promosi (X2) adalah sebesar 2, $294<10,00$, dan variabel citra merek (X3) adalah sebesar $1.909<10,00$. Maka dapat disimpulkan bahwa tidak terjadi multikolinearitas antar variabel bebas, karena nilai Tolerance untuk masing-masing variabel adalah lebih besar dari 0,1 dan nilai VIF untuk masing-masing variabel lebih kecil dari 10,00. 


\section{Uji Autokorelasi}

\begin{tabular}{|l|l|l|l|l|l|}
\multicolumn{7}{|c|}{ Model Summary $^{\mathbf{b}}$} \\
\hline \multirow{2}{*}{ Model } & $\mathrm{R}$ & R Square & $\begin{array}{c}\text { Adjusted } \\
\text { R Square }\end{array}$ & $\begin{array}{c}\text { Std. } \\
\text { Error of } \\
\text { the } \\
\text { Estimate }\end{array}$ & $\begin{array}{c}\text { Durbin- } \\
\text { Watson }\end{array}$ \\
\hline 1 & $.710^{\mathrm{a}}$ & 0.505 & 0.489 & 13.152 & 2.041 \\
\hline
\end{tabular}

a. Predictors: (Constant), Citra Merek, Promosi, Kualitas Produk

b. Dependent Variable: Keputusan Pembelian

Sumber: Hasil Pengolahan Data, 2020

Metode pengujian pada Uji Autokorelasi menggunakan uji Durbin-Watson (uji DW) dengan Nilai DU dapat diperoleh dengan melihat tabel statistik Durbin Watson pada tingkat sig. $\mathrm{a}=5 \%, \mathrm{k}=3$ (jumlah variabel bebas), maka diperoleh nilai DU sebesar 1,734 dengan nilai $\mathrm{n}$ sebesar 98 .

Berdasarkan tabel diatas nilai DW pada penelitian ini adalah sebesar 2.041 dan 4-DU sebesar 2,266. Maka nilai Durbin Watson terletak antara DU $<$ DW $<4$-DU yaitu 1,734 < $\mathbf{2 , 0 4 1}<\mathbf{2 , 2 6 6}$, maka dapat ditarik kesimpulan bahwa tidak terjadi autokorelasi.

\section{Uji Heteroskedistas}

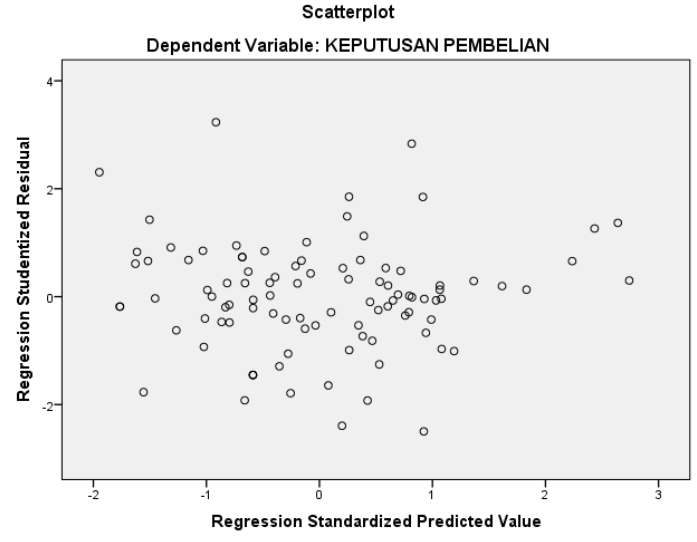

Sumber: Hasil Pengolahan Data, 2020

Berdasarkan data pada Gambar diatas dapat diketahui bahwa titik-titik membentuk pola yang tidak jelas, dan titik-titik menyebar diatas dan dibawah angka 0 pada sumbu Y. Jadi dapat disimpulkan bahwa tidak terjadi heteroskedastisitas dalam model regresi 


\section{Uji Hipotesis}

\section{Uji Koefisien Korelasi}

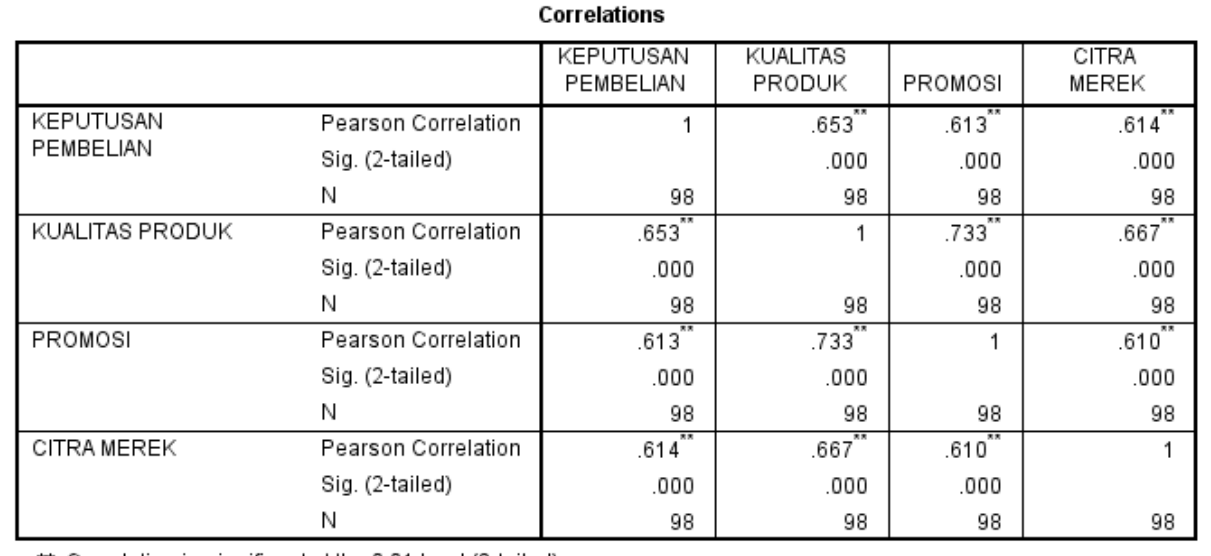

**. Correlation is significant at the 0.01 level (2-tailed).

Sumber: Hasil Pengolahan Data, 2020

Berdasarkan tabel hasil uji koefisien korelasi dapat disimpulkan bahwa:

a. Korelasi Kualitas Produk terhadap Keputusan Pembelian

Diketahui bahwa nilai koefisien korelasi antara variabel kualitas produk terhadap keputusan pembelian konsumen adalah sebesar 0,653 (positif) dan nilai sig. 0,00 $<0,05$. Maka dapat disimpulkan bahwa ada hubungan yang positif dan signifikan antara Kualitas Produk dengan Keputusan Pembelian

b. Korelasi Promosi terhadap Keputusan Pembelian

Diketahui bahwa nilai koefisien korelasi antara variabel kualitas produk terhadap keputusan pembelian konsumen adalah sebesar 0,613 (positif) dan nilai sig. 0,00 $<0,05$. Maka dapat disimpulkan bahwa ada hubungan yang positif dan signifikan antara Promosi dengan Keputusan Pembelian

c. Korelasi Citra Merek terhadap Keputusan Pembelian

Diketahui bahwa nilai koefisien korelasi antara variabel kualitas produk terhadap keputusan pembelian konsumen adalah sebesar 0,614 (positif) dan nilai sig. 0,00 $<0,05$. Maka dapat disimpulkan bahwa ada hubungan yang positif dan signifikan antara Citra Merek dengan Keputusan Pembelian

\section{Analisis Regresi Linier Berganda}

\begin{tabular}{|c|c|c|c|c|c|c|}
\hline \multicolumn{7}{|c|}{ Coefficients $^{a}$} \\
\hline \multirow[b]{2}{*}{ Model } & & \multicolumn{2}{|c|}{ Unstandardized Coefficients } & \multirow{2}{*}{$\begin{array}{c}\begin{array}{c}\text { Standardized } \\
\text { Coefficients }\end{array} \\
\text { Beta }\end{array}$} & \multirow[b]{2}{*}{$t$} & \multirow[b]{2}{*}{ Sig. } \\
\hline & & $B$ & Std. Error & & & \\
\hline 1 & (Constant) & 24.581 & 13.171 & & 1.866 & .065 \\
\hline & KUALITAS PRODUK & .492 & .187 & .308 & 2.632 & .010 \\
\hline & PROMOSI & .300 & .150 & .220 & 2.001 & .048 \\
\hline & CITRA MEREK & .466 & .170 & .275 & 2.741 & .007 \\
\hline
\end{tabular}

Sumber: Hasil Pengolahan Data, 2020 
Berdasarkan tabel diatas hasil uji regresi berganda dapat diketahui sebagai berikut:

$$
Y=24,581+0,492+0,300+0,466
$$

Berikut penjelasan dari persamaan regresi linear berganda diatas sebagai berikut:

a. Nilai konstanta sebesar 24, 581 artinya kualitas produk, promosi, dan citra merek memiliki nilai 24,581

b. Nilai koefisien kualitas produk sebesar 0,492 bernilai positif, artinya bahwa setiap perubahan peningkatan pada satuan variabel kualitas produk akan meningkatkan keputusan pembelian sebesar 0,492

c. Nilai koefisien promosi sebesar 0,300 bernilai positif, artinya bahwa setiap perubahan peningkatan pada satuan variabel promosi akan meningkatkan keputusan pembelian sebesar 0,300

d. Nilai koefisien citra merek sebesar 0,466 bernilai positif, artinya bahwa setiap perubahan peningkatan pada satuan variabel citra merek akan meningkatkan keputusan pembelian sebesar 0,466

\section{Uji F}

Ftabel pada penelitian ini dengan df (jumlah kelompok data -1 ) ini adalah 4-1 = $\mathbf{3}$, df $\mathbf{2}=$ $(\mathbf{n}-\mathbf{k - 1})=\mathbf{9 8 - 3 - 1}=94$. Hasil yang diperoleh Ftabel adalah sebesar 3,090.

ANOVA $^{\mathrm{a}}$

\begin{tabular}{|ll|l|r|r|r|c|}
\hline \multicolumn{2}{|c|}{} & \multicolumn{1}{|c|}{$\begin{array}{c}\text { Sum of } \\
\text { Squares }\end{array}$} & df & Mean Square & F & Sig. \\
\hline 1 & Regression & 16571.744 & 3 & 5523.915 & 31.934 & $.000^{\mathrm{b}}$ \\
& Residual & 16260.103 & 94 & 172.980 & & \\
& Total & 32831.847 & 97 & & & \\
\hline
\end{tabular}

a. Dependent Variable: Keputusan Pembelian

b. Predictors: (Constant), Citra Merek, Promosi, Kualitas Produk

Sumber: Hasil Pengolahan Data, 2020

Berdasarkan Tabel diatas maka diperoleh Nilai Fhitung $>$ Ftabel (31,934 > 3,090) dan nilai sig sebesar $0,000<0,05$ maka dapat disimpulkan bahwa variabel Kualitas Produk, Promosi, dan Citra Merek secara bersamaan atau simultan berpengaruh positif terhadap Keputusan Pembelian. Dengan demikian, Ho ditolak dan Ha diterima.

\section{Uji t}

$\mathrm{t}$ tabel pada penelitian ini dapat dilihat pada tabel sig. 0.05 dengan $\mathrm{df}=\mathrm{n}-\mathrm{k}-1$ atau 98-3-1 =94, maka dapat diketahui t tabel yaitu 1,985

Coefficients $^{\mathrm{a}}$

\begin{tabular}{|ll|r|r|r|r|r|}
\hline \multirow{2}{*}{ Model } & \multicolumn{2}{|c|}{ Unstandardized Coefficients } & \multicolumn{2}{c|}{$\begin{array}{c}\text { Standardized } \\
\text { Coefficients }\end{array}$} & \\
\cline { 2 - 4 } & \multicolumn{1}{|c|}{$\mathrm{B}$} & \multicolumn{1}{|c|}{ Std. Error } & \multicolumn{1}{c|}{ Beta } & \multicolumn{1}{c|}{ Sig. } \\
\hline 1 & (Constant) & 24.581 & 13.171 & & 1.866 & .065 \\
& KUALITAS PRODUK & .492 & .187 & .308 & 2.632 & .010 \\
& PROMOSI & .300 & .150 & .220 & 2.001 & .048 \\
& CITRA MEREK & .466 & .170 & .275 & 2.741 & .007 \\
\hline
\end{tabular}

a. Dependent Variable: KEPUTUSAN PEMBELIAN 
Sumber: Hasil Pengolahan Data, 2020

Berdasarkan tabel diatas hasil uji t, maka dapat di ambil kesimpulan sebagai berikut:

1. Variabel Kualitas Produk (X1) memiliki nilai t hitung $>\mathrm{t}$ tabel yaitu 2,632 > 1,985 dengan nilai sig. $0,010<0,05$. Dengan demikian maka H01 ditolak dan Ha1 diterima, yang artinya secara parsial Kualitas Produk berpengaruh signifikan terhadap Keputusan Pembelian

2. Variabel Promosi (X2) memiliki nilai $t$ hitung $>\mathrm{t}$ tabel yaitu 2,001 $>1,985$ dengan nilai sig. $0,048<0,05$. Dengan demikian maka H02 ditolak dan $\mathrm{Ha} 2$ diterima, yang artinya secara parsial Promosi berpengaruh signifikan terhadap Keputusan Pembelian

3. Variabel Citra Merek (X3) memiliki nilai $t$ hitung $>\mathrm{t}$ tabel yaitu 2,741 $>1,985$ dengan nilai sig. 0,007 $<0,05$. Dengan demikian maka H03 ditolak dan Ha3 diterima, yang artinya secara parsial Citra Merek berpengaruh signifikan terhadap Keputusan Pembelian

\section{Uji Koefisien Determinasi}

\begin{tabular}{|c|c|c|c|c|}
\hline \multicolumn{5}{|c|}{ Model Summary } \\
\hline Model & $\mathrm{R}$ & $\begin{array}{c}\mathrm{R} \\
\text { Square }\end{array}$ & $\begin{array}{l}\text { Adjusted } \\
\text { R Square }\end{array}$ & $\begin{array}{l}\text { Std. Error } \\
\text { of the } \\
\text { Estimate }\end{array}$ \\
\hline & $.710^{\mathrm{a}}$ & 0.505 & 0.489 & 13.152 \\
\hline
\end{tabular}

a. Predictors: (Constant), CITRAMEREK, PROMOSI, KUALITAS PRODUK

Sumber: Hasil Pengolahan Data, 2020

Berdasarkan tabel 4.12, dapat di lihat bahwa nilai menunjukan hasil korelasi sederhana antara Variabel X terhadap Variabel Y memperoleh nilai sebesar 0,710 dan Hal ini menunjukan terjadinya hubungan yang kuat karena nilai diatas 0,05 dan mendekati 1. Sedangkan nilai $\mathrm{R}^{2}$ adalah sebesar 0,505 dan nilai Adjusted $\mathrm{R}^{2}$ sebesar 0,489 . Maka sumbangan pengaruh variabel independen terhadap variabel dependen adalah sebesar $49 \%$. Sedangkan sisanya sebesar $51 \%$ dipengaruhi oleh variabel lain yang tidak masuk ke dalam penelitian ini seperti variabel harga, pelayanan, dll.

\section{KESIMPULAN}

Berdasarkan hasil penelitian yang telah dilakukan mengenai Pengaruh Kualitas Produk, Promosi dan Citra Merek terhadap Keputusan Pembelian Kartu XL Business Solution Pada PT. Activate Asia, maka dapat di tarik beberapa kesimpulan sebagai berikut:

1. Kualitas Produk (X1), Promosi (X2) dan Citra Merek (X3) secara simultan atau bersama-sama berpengaruh terhadap Keputusan Pembelian (Y) Kartu XL Business Solution Pada PT. Activate Asia. 
2. Kualitas Produk berpengaruh terhadap Keputusan Pembelian Kartu XL Business Solution pada PT. Activate Asia

3. Promosi berpengaruh terhadap Keputusan Pembelian Kartu XL Business Solution pada PT. Activate Asia

4. Citra Merek berpengaruh terhadap Keputusan Pembelian Kartu XL Business Solution pada PT. Activate Asia

\section{SARAN}

a. Kualitas Produk

Diharapkan untuk dapat meningkatkan kualitas produk terutama pada point jaringan internet tetap handal di dalam gedung

b. Promosi

Diharapkan untuk dapat meningkatkan promosi Pemasaran Langsung \& Online (Direct \& Online Marketing)

c. Citra Merek

Diharapkan untuk dapat mempertahankan identitas merek, terutama pada logo perusahaan dan citra perusahaan yang sudah terbentuk

\section{Daftar Pustaka}

Buchari Alma. 2018. Manajemen Pemasaran dan Pemasaran jasa, Alfabeta, Bandung.

Duwi Priyatno. 2017. Panduan Praktis Olah Data Menggunakan SPSS,Andi, Yogyakarta.

Fandy Tjiptono dan Anastasia Diana. 2020. Pemasaran, Andi, Yogyakarta.

Kotler dan Keller. 2016. Marketing Management, Pearson Education Limited, England.

M. Syahirman Yusi dan Umiyati Idris. 2020. Statistika Untuk Ekonomi, Bisnis \&

Sosial, Andi, Yogyakarta.

Rizki Kurniawan, Ratmono, dan Nani Septiana. 2018. Pengaruh Harga, Citra

Merek, Kualitas Produk dan Promosi Terhadap Keputusan Pembelian Kartu

Paket Data Internet Telkomsel di Kota Metro, https://stielampungtimur.files.wordpress.com/2020/02/dinamika-5-rizkikurniawan.pdf, diakses pada 2 April 2020.

Sarah Basbeth, Wahyu Hidayat \& Sari Listyorini. 2016. Pengaruh Promosi,

Kualitas Produk, Dan Citra Merek Terhadap Kepuasan Pelanggan Indosat Im3 (Studi Pada Komunitas Im3 Mahasiswa Perguruan Tinggi Negeri di Semarang) https://ejournal3.undip.ac.id/index.php/jiab/article/view/10423, diakses pada 10 Mei 2020

Sri Wahyuni, Jonianto dan Pardemean. 2016. Pengaruh Iklan, Harga Dan Kualitas 
Layanan Terhadap Keputusan Pembelian Kartu Simpati Di Institute Perbanas. https://journal.trunojoyo.ac.id/jsmb/article/view/2565, diakses pada 10 Mei 2020.

Lorensa Agustin Betris N. 2018. Analisis Faktor-Faktor yang Mempengaruhi

Keputusan Pembelian Kartu Prabayar XL Di Surakarta, http://garuda.ristekbrin.go.id/documents/detail/929638, diakses pada 2 April 2020. 